\title{
Reconsolidation blockade for the treatment of addiction: challenges, new targets, and opportunities
}

\author{
Marc T.J. Exton-McGuinness ${ }^{1}$ and Amy L. Milton ${ }^{2}$ \\ ${ }^{1}$ School of Psychology, University of Birmingham, Edgbaston, Birmingham B15 2TT, United Kingdom; ${ }^{2}$ Department of Psychology, \\ University of Cambridge, Downing Site, Cambridge CB2 3EB, United Kingdom
}

\begin{abstract}
Addiction is a chronic, relapsing disorder. The progression to pathological drug-seeking is thought to be driven by maladaptive learning processes which store and maintain associative memory, linking drug highs with cues and actions in the environment. These memories can encode Pavlovian associations which link predictive stimuli (e.g., people, places, and paraphernalia) with a hedonic drug high, as well as instrumental learning about the actions required to obtain drug-associated incentives. Learned memories are not permanent however, and much recent interest has been generated in exploiting the process of reconsolidation to erase or significantly weaken maladaptive memories to treat several mental health disorders, including addictions. Normally reconsolidation serves to update and maintain the adaptive relevance of memories, however administration of amnestic agents within the critical "reconsolidation window" can weaken or even erase maladaptive memories. Here we discuss recent advances in the field, including ongoing efforts to translate preclinical reconsolidation research in animal models into clinical practice.
\end{abstract}

Addiction is a complex disorder believed to be driven by many dysfunctional psychological and neurobiological factors. One prominent account suggests that pathological learning mechanisms drive the cravings, compulsions, and propensity for relapse that characterize the disorder (Everitt et al. 2001; Everitt and Robbins 2005). Given the critical role of maladaptive learning in addiction, significant excitement has arisen at the possibility of erasing, or significantly weakening, memory through targeted disruption of memory reconsolidation - the process by which memories become destabilized under certain conditions of retrieval and require restabilization to persist in the brain (for recent review of the phenomenon see Lee et al. 2017b). Exploiting this phenomenon clinically offers the opportunity to selectively target pathological memories, including those underpinning the propensity for relapse in addiction.

Once a psychological curiosity (Lewis 1979) it is now believed reconsolidation represents a biological process which most, likely all, memories naturally undergo in order to optimize their predictive accuracy (Lee et al. 2017b). Since the initial recognition of the therapeutic potential of reconsolidation blockade for the treatment of addiction (Lee et al. 2005; Miller and Marshall 2005), much research has focused on characterizing potential methods-both pharmacological and behavioral-for memory disruption, and the translation of this preclinical work to human populations. Here, we review current translational studies, discuss alternative pharmacological targets to disrupt reconsolidation, and consider some of the challenges facing the translation of reconsolidation-blockade treatments to the clinic, and how these have been addressed to date.

\section{Early proof-of-principle studies established reconsolidation as a potential therapeutic strategy for relapse prevention in drug addiction}

Reconsolidation presents a promising target for relapse prevention in addiction therapy. Owing to the strong impact of drug-associated

\section{Corresponding author: alm46@cam.ac.uk}

Article is online at http://www.learnmem.org/cgi/doi/10.1101//m.046771.117. cues in precipitating relapse in animal models (Bossert et al. 2013), as well as activating corticostriatal-limbic reward circuitry (for review, see Jasinska et al. 2014)—which correlates with craving measures in drug-addicted humans (Volkow et al. 2006; Sjoerds et al. 2014) - much of the early research into drug memory reconsolidation focused on the reconsolidation of Pavlovian reward memory and its effect on cue-induced relapse (Lee et al. 2005; Milton et al. 2008b). As well as investigating the efficacy of reconsolidation blockade to reduce relapse behavior in animal models, many studies aimed to characterize the molecular mechanisms underpinning Pavlovian drug memory reconsolidation. It was demonstrated, for example, that drug memory reconsolidation depends upon protein synthesis (Valjent et al. 2006; Dunbar and Taylor 2016), ERK signaling (Valjent et al. 2006), activity at NMDA receptors (NMDARs) (Milton et al. 2008a, 2012), and expression of the immediate early gene zif268 (Lee et al. 2005, 2006; Théberge et al. 2010). While providing valuable information on the basic mechanisms of memory persistence and proof-of-principle of the reconsolidation blockade approach, these molecular targets have been rather challenging to translate to human patients.

Consequently, many trials of the reconsolidation blockade approach in humans have focused on less invasive behavioral techniques such as the "retrieval-extinction" procedure (Lee et al. 2017b). This putatively involves destabilizing a memory with an appropriate reactivation session, followed by extinction of the behavior within the "reconsolidation-window" (up to 4-6 h post-reactivation, though typically intervals of $<1 \mathrm{~h}$ are used). In contrast to conventional extinction learning, in which a newly learned memory suppresses the old trace, retrieval-extinction is believed to directly weaken the original memory. However, it remains unclear whether this truly represents "unlearning" or enhanced

C 2018 Exton-McGuinness and Milton This article is distributed exclusively by Cold Spring Harbor Laboratory Press for the first 12 months after the full-issue publication date (see http://learnmem.cshlp.org/site/misc/terms.xhtml). After 12 months, it is available under a Creative Commons License (AttributionNonCommercial 4.0 International), as described at http://creativecommons. org/licenses/by-nc/4.0/. 
extinction, in which case the original cue-drug memory could recover (Baker et al. 2013). Further understanding of the molecular boundaries between reconsolidation and extinction is needed for this question to be addressed (Merlo et al. 2014).

One molecular mechanism of reconsolidation identified by early proof-of-principle studies has received extensive attention due to its more straightforward translation to human studies. Specific aspects of drug memory reconsolidation were shown to require $\beta$-adrenergic receptor ( $\beta \mathrm{AR}$ ) activity (Milton et al. 2008b; although see Milton et al. 2012; Dunbar and Taylor 2016). As the $\beta A R$ antagonist propranolol is approved for human use in treating hypertension, it is readily available for deployment in human experimental medicine trials. Initially these human experiments focused on reconsolidation-disruption of fear memory (Kindt et al. 2009; Brunet et al. 2018) in fear-conditioned healthy participants and patients with post-traumatic stress disorder, due to the more extensive literature on fear memory reconsolidation. More recently however, human reconsolidation studies have begun to investigate reconsolidation as a therapeutic strategy for drug addiction.

\section{Application of reconsolidation blockade treatments to addicted patient populations has produced mixed outcomes}

\section{$\beta A R$ antagonism}

The potential of reconsolidation-based therapies to substantially reduce the impact of drug-associated cues on relapse behavior has begun to be widely recognized, and several studies have attempted to translate rodent findings to human patients. Most studies have used the $\beta A R$ antagonist propranolol as an amnestic agent, given in conjunction with reactivation of the drug-associated cues to destabilize memory; however, outcomes of experimental medicine studies in humans have been mixed. Propranolol was shown to reduce craving in individuals with a range of substance use disorders (Lonergan et al. 2016), however the magnitude of this effect was small and only emerged following multiple reactivation and treatment sessions; follow-up was also limited to $3 \mathrm{wk}$, thus it is unclear whether treatment reduced long-term risk of relapse. Another double-blind trial found cocaine cravings to be reduced $24 \mathrm{~h}$ after propranolol administration with memory reactivation (Saladin et al. 2013), but this effect had dissipated after just 1 wk. Thus, current propranolol treatments appear to have limited long-term impact. Moreover, several negative findings exist. Pachas et al. (2015) found no effect of propranolol treatment on nicotine craving, and one study even found cocaine craving to be enhanced by giving propranolol at reactivation (Jobes et al. 2015). This highlights the potential risks of our lack of understanding of reconsolidation and its relationship to extinction. It is also worth highlighting that several individuals in these studies were polydrug users and undergoing continuing treatment (Jobes et al. 2015; Lonergan et al. 2016), which may present problems for backtranslation, as animal models of addiction typically only investigate a single drug-of-abuse and a single treatment in isolation.

Why might these mixed results have arisen with the use of propranolol to disrupt drug memory reconsolidation? Adrenergic signaling has been shown to bidirectionally modulate memory strength during the reconsolidation window. For example, enhancement of adrenergic signaling with the prodrug dipivefrin within the reconsolidation window enhances the conditioned reinforcing properties of an alcohol-paired cue, thereby facilitating its ability to support the acquisition of a new response for conditioned reinforcement; while propranolol, but not the peripherally acting adrenergic receptor antagonist nadolol, weakened the same memory (Schramm et al. 2016). Propranolol has also been shown to reverse cocaine-mediated synaptic modifications in the prelimbic mPFC following memory reactivation (Otis and Mueller 2017), supporting the view that the drug is directly affecting synaptic plasticity.

Notably, propranolol has only been demonstrated to disrupt certain types of drug memory, with some key negative findings. Reconsolidation-disruption with propranolol does not reduce cueinduced reinstatement of cocaine-seeking (Milton and Everitt 2009; Dunbar and Taylor 2016), and similarly does not disrupt the reconsolidation of memories underlying Pavlovian conditioned approach or instrumental-transfer for alcohol-associated cues (Milton et al. 2012). Blockade of $\beta$ ARs has also been shown to disrupt the reconsolidation of conditioned hyperactivity, but not locomotor sensitization to morphine (Wei and Li 2014). Propranolol administration directly to the basolateral amygdala (BLA) did not disrupt reconsolidation of place aversion associated with morphine withdrawal (Wu et al. 2014)—although it did disrupt morphine-conditioned place preference when infused into the BLA (Otis et al. 2013; Wu et al. 2014) or central nucleus of the amygdala (CeN) (Zhu et al. 2017). However propranolol had no effect on the reconsolidation of the memories underlying cocaine-conditioned place preference (CPP) when infused into the dorsal hippocampus, despite an acute impairment of retrieval (Otis et al. 2014). Wu et al. (2014) also observed no effect on either the reconsolidation of a morphine-conditioned place preference or withdrawal-conditioned place aversion with the $\alpha$-noradrenergic receptor antagonist phentolamine. Together these results suggest that amygdala $\beta$ ARs play a limited role in the reconsolidation of a small number of types of drug memories-namely CPP and conditioned reinforcement-which likely accounts for the lack of effect on cue-induced reinstatement (see Milton and Everitt 2010) and the mixed results with propranolol in human trials.

\section{NMDAR antagonism}

An alternative pharmacological target is the NMDAR, consistent with previous observations that NMDAR antagonists disrupt the reconsolidation of drug memories (Alaghband and Marshall 2013; Alaghband et al. 2014) and the findings of a meta-analysis that indicated a greater effect of NMDAR antagonism on memory reconsolidation than $\beta$ AR antagonism (Das et al. 2013). However, despite previous animal literature and the findings of Vengeliene et al. (2015), that NMDAR antagonism with memantine at reactivation reduced subsequent cue-induced relapse in alcohol-seeking rats, memantine proved ineffective at reducing nicotine cravings in human smokers (Das et al. 2015) - and there may even have been some evidence of a worsening of symptoms. There are several potential explanations for the mixed effects of memantine. First, the effects of memantine on cue-induced relapse to alcoholseeking in rats was not reactivation-dependent (Vengeliene et al. 2015), although only animals that had received memantine in conjunction with reactivation showed impaired reacquisition following extinction. This suggests NMDAR antagonism may have effects on drug seeking independent of its amnestic potency. Second, memantine has relatively slow kinetics, meaning the drug must be administered prior to memory reactivation. This is potentially problematic as different subtypes of NMDAR are differentially involved in the destabilization and restabilization of memories, so prereactivation administration may have an impact on memory destabilization mechanisms. Findings from fear memory reconsolidation indicating a double dissociation in the requirement for GluN2B- and GluN2A-containing NMDARs for memory destabilization and restabilization, respectively (Ben Mamou et al. 2006; Milton et al. 2013) have subsequently been supported in studies of drug memory reconsolidation, with GluN2B-containing NMDARs mediating the destabilization of methamphetamine-associated 
memories (Yu et al. 2016) and GluN2A-containing NMDARs being critical for the restabilization of drug memories following reactivation (Wells et al. 2016; Hafenbreidel et al. 2017). Since memory destabilization is also blocked by antagonism at NMDARs it may be that memantine prevented reconsolidation from taking place-indeed the protective effect of memantine on memory, and slow kinetics, is what makes it attractive as a treatment option for Alzheimer's disease. The relatively low affinity of memantine for synaptic NMDARs may also make it a suboptimal choice for disrupting memory reconsolidation (Rammes et al. 2008; see also Das et al. 2015 for discussion).

Clinically, antagonizing GluN2A subunits of the NMDAR therapeutically may maximize the benefits of reconsolidationdisruption, while not blocking the GluN2B subunits required for destabilization (and therefore required for any clinical effect to take place). Moreover, targeting a single NMDAR subunit may be more effective than universal antagonism (Wang et al. 2012), and may also minimize psychotomimetic side effects (JiménezSánchez et al. 2014).

\section{Improving the efficacy of reconsolidation-blockade in human trials}

How can the success of reconsolidation trials in humans be increased? The recent literature has focused on three major strategies: (i) the identification of new pharmacological targets; (ii) the disruption of other instrumental, rather than Pavlovian, associations, and; (iii) optimizing the reactivation procedure to enhance memory destabilization, by furthering knowledge of the "boundary conditions" that place limits on reconsolidation.

\section{Alternative pharmacological targets for the disruption of drug memories}

An obvious possibility to improve the translation of treatments based on reconsolidation blockade is the choice of pharmacological target. Propranolol is generally less effective than NMDAR antagonism (Milton et al. 2012; Dunbar and Taylor 2016); however, NMDAR antagonists can have unacceptable side effects and chronic use may result in cognitive deficits (Morgan et al. 2010). An alternative may be to target other molecular mechanisms underlying reconsolidation, or behavioral methods of modifying memory such as retrieval-extinction (Xue et al. 2012; Luo et al. 2015) or the application of a high cognitive load (Kaag et al. 2018). Another possibility is to administer an agent which will enhance the destabilization of a memory and promote the engagement of reconsolidation processes. In principle this is possible and has been demonstrated for fear memory by agonizing cannabinoid receptors (Lee and Flavell 2014) and NMDARs (Bustos et al. 2010); moreover, this would benefit both behavioral and pharmacological methods of memory alteration. Knowledge of the molecular and neurochemical mechanisms underlying reconsolidation has advanced in recent years and has characterized the process from the (epi)genetic to cell-surface signaling levels, revealing new targets-of-interest for reconsolidation-disruption which might be a focus for new treatment development, even if not all can be targeted with current pharmacotherapies.

\section{Epigenetic regulation}

Significant attention has been recently focused on the epigenetic regulation of gene expression (Oliveira 2016), and epigenetic mechanisms have been demonstrated to play a role in reconsolidation of Pavlovian drug memories. Administration of the histone acetyl-transferase inhibitor garcinol blocked the reconsolidation of cue-cocaine memory, disrupting conditioned reinforcement (Monsey et al. 2017) and preventing cue-induced relapse (Dunbar and Taylor 2017). Shi et al. (2015) also demonstrated that inhibition of DNA methyl-transferase activity in the BLA following reactivation of drug memory prevented cue- and drug-induced relapse. In contrast, histone deacetylase inhibitors appear to enhance learning, and may facilitate extinction similarly to the retrieval-extinction procedure-resulting in a "superextinction" which does not recover over time (see Lattal and Wood 2013 for discussion). Importantly, histone deacetylase inhibitors are surprisingly well-tolerated given their current use as anti-cancer medication (Subramanian et al. 2010); many side effects are reversible and resolve quickly, meaning they may be highly clinically viable in an acute intervention such as reconsolidation blockade.

\section{Immediate early gene expression}

It has been long known that reconsolidation of cue-drug memory requires expression of the immediate early gene (IEG) zif268 in the amygdala (Lee et al. 2005) and nucleus accumbens (Théberge et al. 2010). More recent research has indicated that the expression of this gene is increased at a vast number of neural loci following memory reactivation, including the medial prefrontal cortex, hippocampus, and ventral tegmental area (Li et al. 2016). Interestingly Li et al. (2016) also observed that coantagonism of the $\mathrm{D}_{1}$-subtype of dopamine receptor $\left(\mathrm{D}_{1} \mathrm{R}\right)$ and NMDARs in the nucleus accumbens shell prevented increases in zif268 expression in multiple neurobiological reward loci, consistent with previous behavioral research showing that coantagonism of these receptors in the nucleus accumbens prevents appetitive memory reconsolidation (ExtonMcGuinness and Lee 2015). Thus, the nucleus accumbens may be a vital coordinating hub for appetitive memory reconsolidation.

Recently attention has been directed toward the IEG arc. Expression of Arc is greatly increased following reactivation of memories underlying cocaine CPP (Alaghband et al. 2014; Lv et al. 2015), and conditioned place aversion to morphine withdrawal (García-Pérez et al. 2016). These increases in Arc were also associated with elevated phosphorylation of CREB ( $\mathrm{Lv}$ et al. 2015; García-Pérez et al. 2016) and appear to be caused by ERK signaling upstream, as the MEK inhibitor U0126 prevented phosphorylation of ERK and CREB, and disrupted reconsolidation of morphine CPP (Lv et al. 2015). Surprisingly, García-Pérez et al. (2016) suggest that dysregulation of CREB signaling may in fact enhance reconsolidation, rather than impair it. On the other hand, as one might anticipate, knockdown of Arc expression with antisense oligodeoxynucleotides prevented reconsolidation of CPP and weakened later memory expression (Lv et al. 2015). Notably, the precise mechanism by which Arc exerts effects on memory has recently been called into question. Two studies have suggested Arc may mediate intercellular communication by transferring mRNA across synapses (Ashley et al. 2018; Pastuzyn et al. 2018). Thus, the amnestic effect of Arc knockdown may be due to blockade of intercellular communication, rather than the gene in and of itself contributing to intracellular memory storage. A greater understanding of how an individual neuron communicates with its neighbors may reveal more targets for novel drug development.

\section{Protein synthesis and proteolysis}

Inhibition of protein synthesis is viewed as the canonical amnestic intervention-linking changes in memory strength to biological expression of new protein. Several studies have added to this understanding, demonstrating blockade of drug memory reconsolidation using protein synthesis inhibitors such as anisomycin (Yu et al. 2013; Wu et al. 2014; Sorg et al. 2015; Dunbar and Taylor 2016), cycloheximide (Escosteguy-Neto et al. 2016) and rapamycin (Barak et al. 2013; Lin et al. 2014). Of particular interest, 
Escosteguy-Neto et al. (2016) observed an extended window of protein synthesis dependence following reactivation of a contextmorphine memory, requiring multiple injections of cycloheximide to disrupt the association. While the authors suggest that consolidation and reconsolidation mechanisms may have been triggered together, this result may represent differences in efficacy between anisomycin and cycloheximide-either on protein synthesis blockade, or intracellular signaling and IEG expression (Zinck et al. 1995). Certainly, disrupting the consolidation of the memories underlying morphine CPP requires repeated cycloheximide injections (Milekic et al. 2006). However, this result raises interesting questions about the duration of the reconsolidation window and the requirement for protein synthesis, the duration of which may depend upon the reactivation procedure used to destabilize the memory. Further investigation is required to understand both the duration of initial protein synthesis dependence, and whether multiple rounds of protein synthesis occur following destabilization and reconsolidation of a memory as is the case for memory consolidation (Bekinschtein et al. 2007, 2010).

One problem associated with the therapeutic use of protein synthesis inhibitors is their high toxicity; however, alternative targets may prove fruitful in the future. Jian et al. (2014) observed dephosphorylation of eukaryotic initiation factor $2 \alpha$-subunit (eIF2 $\alpha$ ) and activating transcription factor 4 (ATF4) in the BLA, but not $\mathrm{CeN}$, following the reactivation of memories underlying both cocaine and morphine CPP. Furthermore, preventing this dephosphorylation with local infusion of the selective eIF2 $\alpha$ phosphatase inhibitor Sal003 also blocked reconsolidation of cocaine and morphine CPP, and cue-heroin memory. Interestingly, knockdown of ATF4 with shRNA protected memory from amnesia, suggesting that ATF4 may be required for the destabilization of the memory at reactivation.

While protein synthesis has long been linked with the consolidation and reconsolidation of memories, protein degradation is hypothesized to play a role in memory destabilization. Infusion of the proteasome inhibitor lactacystin into the nucleus accumbens core prior to memory reactivation protected against the amnestic effect of anisomycin (Ren et al. 2013), with this treatment also maintaining levels of the AMPAR GluR2-subunit expression at the synapse. Notably lactacystin also prevented the extinction of $\mathrm{CPP}$, suggesting that protein degradation may be a more general requirement for synaptic plasticity to occur. However, inhibition of the protease calpain in the nucleus accumbens core has recently been shown to disrupt reconsolidation of cocaine and morphine cue memory (Liang et al. 2017). This contrasts with previous studies which have suggested protein degradation mediates memory destabilization, rather than reconsolidation. Therefore, a more complex dynamic cycling of proteins may be required for neuronal plasticity.

\section{Protein phosphorylation}

Reconsolidation is regulated by multiple protein kinases. In line with previous studies, ERK activity in the BLA (Wells et al. 2013) and nucleus accumbens shell (Lv et al. 2015) is required for the reconsolidation of contextual drug memory, and BLA inhibition of CaMKII $\alpha$ has been shown to disrupt reconsolidation and enhance extinction of cue-cocaine memory, being differentially regulated in both processes (Rich et al. 2016). By contrast PKA, but not CaMKII $\alpha$, in the BLA was found to be required for reconsolidation of context-cocaine memory (Arguello et al. 2014). Notably, the precise role for PKA has been called into question with the discovery of a parallel cAMP-dependent pathway. Activation of Exchange Protein activated by cAMP (Epac) has been shown to disrupt reconsolidation of cue-cocaine memory, and this amnestic effect was rescued by coactivation of PKA (Wan et al. 2014). Thus PKA may play roles in both the destabilization and reconsolidation of memories (see also Sanchez et al. 2010).

Two further kinases of interest are the Src family of tyrosine kinases (SFK) and glycogen synthase kinase (GSK), and these may present interesting future drug targets. Administration of the GSK3 inhibitor SB216763 immediately after cocaine CPP memory reactivation reduced subsequent place preference (Shi et al. 2014). Similarly, Wells et al. (2016) demonstrated that SFKs are required in the dorsal hippocampus for reconsolidation of contextual cocaine memory. Furthermore, this group observed increased phosphorylation of the NMDAR subunit GluN2A following memory reactivation. Moreover, blockade of GluN2A phosphorylation with the SFK inhibitor PP2, or treatment with the GluN2A-selective NMDAR antagonist PEAQX, in the dorsal hippocampus disrupted cocaine memory reconsolidation. This is consistent with the prior dissociation of roles for GluN2A and GluN2B subunits in fear memory restabilization and destabilization, respectively (Milton et al. 2013).

Conversely, blockade of GluN2B-containing NMDARs prevented destabilization of methamphetamine CPP memory ( $\mathrm{Yu}$ et al. 2016). This required downstream activation of protein phosphatase 1 (PP1) by calcineurin; inhibition of either of these phosphatases prevented destabilization and protected against amnesia. Yu et al. (2016) also observed a reduction in AMPAR:NMDAR ratio following destabilization, and suggest that destabilization may be causally linked to internalization of AMPARs. Consistent with this view, Yu et al. (2013) found that preventing AMPAR endocytosis with the interfering peptide Tat-Glu $2_{3 \gamma}$ prevented destabilization of methamphetamine context memory.

\section{Dopamine receptors}

Interestingly NMDARs in the nucleus accumbens may interact with the $D_{1}$-subtype of dopamine receptor in the reconsolidation of drug memory, by regulating expression of the IEG zif268 ( $\mathrm{Li}$ et al. 2016). Antagonism at $D_{1}$ Rs, or knockout of $D_{3} R s$, can weaken the reconsolidation of cocaine CPP (Yan et al. 2014). While this result should be interpreted with caution as blockade of dopamine receptors may affect the reinforcing capacity of cocaine, this result did not appear to be dose-dependent therefore may truly represent a reconsolidation impairment.

It is not yet clear whether dopamine receptors play a role in drug memory destabilization. This has begun to be characterized for Pavlovian memories associated with natural reinforcers such as sucrose (Merlo et al. 2015), and dysregulation of VTA dopamine signaling can prevent destabilization of appetitive sucrose memory (Reichelt et al. 2013). The prediction error hypothesis of memory destabilization implies this should also be true for drug memories, however this as yet remains untested.

\section{Cannabinoids}

Cannabidiol has been shown to disrupt reconsolidation of morphine and cocaine CPP (de Carvalho and Takahashi 2017). Previous work from the same group suggested blockade of $\mathrm{CB}_{1}$, but not $\mathrm{CB}_{2}$ receptors, led to disruption of morphine CPP (De Carvalho et al. 2014). They also observed that inhibiting anandamide metabolism at reactivation led to an enhancement of morphine CPP, suggesting that endocannabinoid signaling may bidirectionally modulate memory strength.

The precise mechanism of cannabidiol's mnemonic effects is unclear, although its therapeutic potential is beginning to be appreciated. It may be that it is directly disrupting reconsolidation, but it may also enhance extinction (Stern et al. 2018). Alternatively, cannabidiol may be more generally anxiolytic, leading to an "updating" of a memory's salience during the reconsolidation window, in addition to acute reductions in drug memory 
expression (Lee et al. 2017a). This would imply the effect of cannabidiol is mediated via the stress-axis.

\section{Glucocorticoids}

Blocking glucocorticoid receptors with mifepristone disrupted the reconsolidation of morphine CPP and morphine sensitization (Fan et al. 2013). While this also prevented initial acquisition, suggesting perhaps an effect on the rewarding value of the drug, mifepristone did not in itself cause place aversion. In a similar study, Stringfield et al. (2017) demonstrated the effect of mifepristone was reactivation-dependent; however, they observe an inverted dose-response relationship, and similar results when mifepristone was given in conjunction with novelty stress. Together this suggests that glucocorticoids do not mediate reconsolidation of drug memory per se, although they may act synergistically to enhance the process.

\section{Cytoskeleton}

A novel target for disrupting reconsolidation may be cytoskeletal proteins. Inhibiting actin polymerization in the nucleus accumbens shell weakened morphine CPP reconsolidation ( $\mathrm{Li}$ et al. 2015), although Briggs et al. (2017) observed disruption of amphetamine (but not cocaine or morphine) CPP reconsolidation with inhibition of nonmuscle myosin II in the BLA. This latter result is of interest, as targeting the nonmuscle myosin would be more viable therapeutically than systemic blockade of actin polymerization (which is required for normal muscle and heart function).

Similarly, local infusion of NSC23766-an inhibitor of the small GTPase Rac, which modulates actin dynamics (Jaffe and Hall 2005)—into the BLA blocked the reconsolidation of cocaine CPP (Ding et al. 2013). Notably the initial consolidation of this memory required Rac activity in BLA in addition to the CeN and nucleus accumbens core, but not the nucleus accumbens shell. While results of cytoskeleton manipulation on reconsolidation have varied between different drugs, commonalities will likely emerge with future research.

\section{Extraneuronal targets}

Neurons and synapses are encompassed by extracellular matricesperineuronal nets (PNNs). These nets help stabilize neuronal connections and regulate synaptic plasticity (Wang and Fawcett 2012), and intact perineuronal nets in the MPFC are necessary for reconsolidation of cocaine CPP (Slaker et al. 2015). Interestingly, removal of PNNs took place $3 \mathrm{~d}$ prior to memory reactivation, thus the loss of PNNs need not occur within the reconsolidation window to disrupt later restabilization of memory.

Normal function of neurons is also supported by local astrocytes and preventing supply of astrocyte-derived lactate can prove amnestic. Local inhibition of glycogen phosphorylase in the BLA prior to memory retrieval disrupted cocaine CPP reconsolidation (Boury-Jamot et al. 2016; Zhang et al. 2016); moreover this effect involved ERK- and zif268-dependent mechanisms, but not BDNF (Boury-Jamot et al. 2016). This intervention also prevented reconsolidation of cued cocaine self-administration (Zhang et al. 2016).

\section{Instrumental memory reconsolidation as a potential therapeutic target}

To date most research and human trials have focused on Pavlovian memory reconsolidation, owing to the extensive literature-partly from studies of Pavlovian conditioned fear-yet instrumental associations between actions and drug acquisition also play a critical role in addiction (Milton and Everitt 2012). However, early demonstrations suggested that instrumental memories did not reconsoli- date (Mierzejewski et al. 2009; Hernandez and Kelley 2004). This has now been challenged by recent demonstrations that expression of operant responses can be disrupted by targeting reconsolidation. First demonstrated in operant sucrose memory using the amnestic NMDAR antagonist MK-801 (Exton-McGuinness et al. 2014), this result has since been replicated for weakly trained cocaine-reinforced memory (Exton-McGuinness and Lee 2015).

Instrumental behaviors are believed to be supported by two memory associations: an Action-Outcome (A-O) association mediating goal-directed responding, and a Stimulus-Response (S-R) habit (see Balleine and O'Doherty 2010 for review). An influential view of addiction asserts that the disorder is driven by formation of a maladaptive habit, given the clear similarities between the theoretical definition of habits and the symptoms of substance use disorders (Tiffany et al. 2004; Everitt and Robbins 2005; Ostlund and Balleine 2008) and shifts in the reliance on different striatal circuitry as drug-seeking experience becomes more extensive (Vanderschuren et al. 2005; Belin et al. 2009; Murray et al. 2012). However emerging evidence has demonstrated that drug-seeking can be supported by goal-directed processes in both humans (Hogarth and Chase 2011; Hogarth 2012) and rodent models (Zapata et al. 2010; Singer et al. 2018). This has led to the rise of an alternative theoretical account of addiction which emphasizes incentive processing and behavioral flexibility (Robinson and Berridge 2008). Fundamentally these two hypotheses place differing emphasis on the respective roles of cue-driven (S-R) and incentive $(\mathrm{A}-\mathrm{O})$ behaviors to explain the compulsion to seek drugs, however both are believed to influence drug-seeking behavior in addicted humans (Hogarth and Chase 2011). Thus, both are viable psychological targets for therapeutic intervention.

Published literature to date has demonstrated reconsolidation of weakly trained, and therefore presumably goal-directed, instrumental cocaine memory (Exton-McGuinness and Lee 2015). A further study also suggested disruption of an older instrumental memory could prevent reinstatement of nicotine seeking (Tedesco et al. 2014), however this impairment was observed as a failure to reinstate; thus, it is unclear whether this truly represents a disruption of instrumental memory, or instead contextual drug memory. Regardless, together these results indicate that in principle operant incentive-based associations can be disrupted-presenting a new psychological target for reconsolidation therapies. Future human experimental medicine trials may disrupt this new psychological target as a means of promoting drug abstinence; however, this will require modification (and optimization) of behavioral reactivation parameters to maximize the probability of the target memory being destabilized (see Das et al. 2015 for discussion). Moreover, targeting both Pavlovian and instrumental associations is likely to provide the most effective anti-relapse intervention. Thus, the most potent treatments may require reconsolidationdisruption targeting several individual memories.

It remains unclear whether reconsolidation of habit memories can be disrupted. While similar methods have been used to disrupt well-learned instrumental cocaine seeking memory (ExtonMcGuinness MTJ, Drame ML, Kaila J, Walsh H, Flavell C, Lee JLC, in prep.), the interpretation is complicated by the observation that responding appears to be rendered functionally goal-directed following successful destabilization of instrumental memory, even in control groups; similar findings were observed for sucrose memory (Exton-McGuinness et al. 2014). Importantly, amnesia is not total in these interventions suggesting only one of A-O or $\mathrm{S}-\mathrm{R}$ memory is disrupted; however, it remains unclear which association is impaired without further investigation. A further alternative account is that the remaining responding in these experiments is supported by a Pavlovian conditioned response-or "incentive habit" (Belin et al. 2013). The precise associative structure driving the compulsion to seek drugs, and the boundaries 
between Pavlovian versus instrumental associations, is a highly interesting topic, and expanding our understanding will be vital to appropriately targeting future clinical interventions.

\section{Identifying, and overcoming, boundary conditions on reconsolidation}

To make reconsolidation blockade maximally efficacious, further work is needed to optimize the parameters of the reactivation session. Following initial demonstrations in crabs (Pedreira and Maldonado 2003), it is becoming increasingly acknowledged that reconsolidation does not always occur following retrieval, instead requiring prediction error to initiate the destabilization process (Exton-McGuinness et al. 2015)—indeed this may explain several negative findings with reconsolidation-based procedures in humans. Hon et al. (2016) recently demonstrated that prediction error induced by omission, but not value change, affected later verbal fluency for alcohol-associated memories in at-risk drinkers. Several human trials have utilized script-based reactivation procedures which may not be effective at triggering the appropriate prediction error for reconsolidation to take place (Pachas et al. 2015). Certain methods of generating a suitable prediction error will likely be more effective than others in clinical practice, and optimization will be required to produce the most favorable therapeutic outcomes (Elsey and Kindt 2017).

How might reactivation be optimized? Conventional reactivation procedures involve reexposure to the training scenario in the absence of the reward, or unconditioned stimulus (US), i.e., extinction. While brief reexposure sessions do appear to trigger reconsolidation, extended CS exposure leads to extinction learning (Reichelt and Lee 2012; Flavell and Lee 2013; Merlo et al. 2014; Cassini et al. 2017) involving the formation of a new inhibitory memory (Bouton 2004); and in this case reconsolidation appears to be endogenously blocked by cellular machinery (Merlo et al. 2014). Interestingly, intermediate numbers of CS exposures trigger neither reconsolidation nor extinction (Flavell and Lee 2013; Merlo et al. 2014; Cassini et al. 2017), and at least for fear memory this "limbo" is associated with the arrest of ERK signaling in the amygdala (Merlo et al. 2018). Since reconsolidation does not appear to occur following simple retrieval when a memory is welllearned, it may be that the limbo state between reconsolidationmediated updating and behavioral extinction is biologically adaptive-representing the default cellular mode of memory retrieval. Expanding our understanding of the molecular underpinnings of this process may help us to artificially stimulate destabilization outside of the conventional boundary conditions, which would in turn enhance the efficacy of therapeutic interventions.

One method used to circumvent the boundary conditions of nonreinforced reactivation procedures is reexposure to the reinforcer-a "US-reactivation." For example, Barak et al. (2013) successfully disrupted alcohol memory in rats using rapamycin by presenting US sensory-specific cues (smell, taste); these cues successfully reactivated memory even when presented outside the training context. Similarly, US-reactivation has successfully been used to destabilize nicotine (Xue et al. 2017) and cocaine (Dunbar and Taylor 2017; Zhu et al. 2017) memories. Notably these US-reactivations were able to simultaneously disrupt multiple memory traces, either preventing reinstatement produced by multiple cues (Dunbar and Taylor 2017), or in the case of Xue et al. (2017) and Zhu et al. (2017) weakening both CPP and operant responding. Moreover, by tagging reactivated neural ensembles Xue and colleagues were able to show overlapping circuitry between these memory traces.

While it is intuitively appealing to believe that US-reactivations destabilize multiple memory traces, these results should be interpreted with caution. It has long been known that incentive memories for the value of reinforcers themselves undergo reconsolidation following reexposure to the reward/US (Wang et al. 2005). Encoding the incentive value of a reinforcer is vital to the functioning of any outcome-based memory association, and disrupting it will reduce expression of all outcome-associated behaviors in a goal-directed fashion (see Dickinson and Balleine 1994 for discussion). The value of an outcome is likely commonly encoded between associations, explaining the overlapping of circuitry; however, this also means that following reward revaluation (e.g., drug reexposure) responding could be rapidly restored. This possibility has not been explicitly tested following a US-reactivation procedure, however it would be consistent with the interpretation that reconsolidation impairments are highly content limited (Debiec et al. 2006). Thus, it remains unclear whether this method of memory destabilization and disruption is sufficient to provide an effective anti-relapse intervention.

Others have sought to deliberately target the incentive value of predictive cues by counterconditioning within the reconsolidation window. In a CPP study in mice, Goltseker et al. (2017) paired a previously cocaine-paired compartment with lithium chloride malaise following brief context reexposure. Critically for future therapeutic application, this immediately suppressed preference for the previously cocaine-paired compartment and moreover this effect was resistant to cocaine-induced relapse. In a human variation of this procedure, pairing alcohol cues with disgust during the reconsolidation window later reduced cue-induced craving and weakened attentional bias toward the cues (Das et al. 2018).

\section{Conclusions and future directions}

Several new pharmacological, readily translatable, treatment targets have been identified for Pavlovian drug memory reconsolidation, including garcinol and cannabidiol. Evidently, treatments targeting receptor systems (e.g., dopamine receptors or glucocorticoid receptors) present currently more feasible therapeutic targets than intracellular systems (e.g., treatments targeting the cytoskeleton, or immediate early gene expression) but future research may reveal methods for indirectly targeting these, such as the reduction of Zif268 expression produced by NMDAR antagonism following the reactivation of cocaine-associated memories (Milton et al. 2008a). The demonstration that instrumental memories also undergo reconsolidation opens exciting new avenues in preventing relapse. However, it remains unclear whether stimulus-based or incentive-based processes are disrupted by these interventions, and it is likely that both will need to be targeted for the most effective anti-relapse treatment.

Future clinical work should build on what is currently known, while basic research should continue to characterize the mechanisms that underlie reconsolidation and probe its potential limits (or not) in more translationally relevant procedures. Clinical studies should continue to refine reactivation parameters, with one possibility currently showing promise being US-based reactivation procedures. However, this should be approached with some caution, as it is unclear whether these interventions will prove resistant to subsequent revaluation of the US; there are also ethical issues regarding administering drugs to individuals who are trying to remain abstinent. It is currently unclear whether peripherally acting drugs in the same class could be used as an alternative (or drugs with differing kinetics e.g., methadone versus heroin) to reactivate memory. Furthermore, it remains to be investigated whether these alternatives could be used to create a viable reconsolidation-based counterconditioning procedure that could be applied to human clinical populations. 
Finally, despite a growing literature, no reconsolidation studies have yet looked at compulsive drug use. While such experiments are technically and conceptually highly challenging, this research is very important for successful translation of reconsolidationbased therapies from bench to bedside. Whether compulsive habits are susceptible to reconsolidation blockade is a key question with high translational relevance.

Thus, reconsolidation blockade offers a highly innovative approach for the treatment of drug addiction and, despite some mixed results, there are studies proving its relevance and potential therapeutic use in humans. We would suggest that the field now needs to move beyond these initial proof-of-principle studies to optimization of the procedure, taking a multipronged approach of: (i) identifying the most readily translatable (combination of) pharmacological targets through a better understanding of the basic neurochemical and molecular mechanisms of reconsolidation, (ii) determining the optimal procedure for memory reactivation (including how to identify when destabilization has successfully occurred), and (iii) determining the effects of targeting Pavlovian memories, instrumental associations (both goal-directed and habitual), or both on subsequent drug-seeking and drug-taking behavior. Despite the challenges to translation, reconsolidation blockade presents a real opportunity to revolutionize the treatment of addiction.

\section{Acknowledgments}

M.T.J.E.-M. is supported by the UK Medical Research Council (MR/M017753/1). A.L.M.'s research is supported by the Wellcome Trust $(200710 / \mathrm{Z} / 16 / \mathrm{Z})$ and the Medical Research Council (MR/N02530X/1) and she is the Ferreras-Willetts Fellow in Neuroscience at Downing College, Cambridge.

\section{References}

Alaghband Y, Marshall JF. 2013. Common influences of non-competitive NMDA receptor antagonists on the consolidation and reconsolidation of cocaine-cue memory. Psychopharmacology (Berl) 226: 707-719.

Alaghband Y, O’Dell SJ, Azarnia S, Khalaj AJ, Guzowski JF, Marshall JF. 2014. Retrieval-induced NMDA receptor-dependent Arc expression in two models of cocaine-cue memory. Neurobiol Learn Mem 116: 79-89.

Arguello AA, Hodges MA, Wells AM, Lara H, Xie X, Fuchs RA. 2014. Involvement of amygdalar protein kinase A, but not calcium/ calmodulin-dependent protein kinase II, in the reconsolidation of cocaine-related contextual memories in rats. Psychopharmacology (Berl) 231: $55-65$.

Ashley J, Cordy B, Lucia D, Fradkin LG, Budnik V, Thomson T. 2018. Retrovirus-like gag protein arc1 binds RNA and traffics across synaptic boutons. Cell 172: 262-274.e11.

Baker KD, McNally GP, Richardson R. 2013. Memory retrieval before or after extinction reduces recovery of fear in adolescent rats. Learn Mem 20: 467-473.

Balleine BW, O'Doherty JP. 2010. Human and rodent homologies in action control: corticostriatal determinants of goal-directed and habitual action. Neuropsychopharmacology 35: 48-69.

Barak S, Liu F, Ben Hamida S, Yowell QV, Neasta J, Kharazia V, Janak PH, Ron D. 2013. Disruption of alcohol-related memories by mTORC1 inhibition prevents relapse. Nat Neurosci 16: 1111-1117.

Bekinschtein P, Cammarota M, Igaz LM, Bevilaqua LRM, Izquierdo I, Medina JH. 2007. Persistence of long-term memory storage requires a late protein synthesis- and BDNF- dependent phase in the hippocampus. Neuron 53: 261-277.

Bekinschtein P, Katche C, Slipczuk L, Gonzalez C, Dorman G, Cammarota M, Izquierdo I, Medina JH. 2010. Persistence of long-term memory storage: new insights into its molecular signatures in the hippocampus and related structures. Neurotox Res 18: 377-385.

Belin D, Jonkman S, Dickinson A, Robbins TW, Everitt BJ. 2009. Parallel and interactive learning processes within the basal ganglia: relevance for the understanding of addiction. Behav Brain Res 199: 89-102.

Belin D, Belin-Rauscent A, Murray JE, Everitt BJ. 2013. Addiction: failure of control over maladaptive incentive habits. Curr Opin Neurobiol 23: 564-572.
Ben Mamou C, Gamache K, Nader K. 2006. NMDA receptors are critical for unleashing consolidated auditory fear memories. Nat Neurosci 9: 1237-1239.

Bossert JM, Marchant NJ, Calu DJ, Shaham Y. 2013. The reinstatement model of drug relapse: recent neurobiological findings, emerging research topics, and translational research. Psychopharmacology (Berl) 229: 453-476.

Boury-Jamot B, Carrard A, Martin JL, Halfon O, Magistretti PJ, Boutrel B. 2016. Disrupting astrocyte-neuron lactate transfer persistently reduces conditioned responses to cocaine. Mol Psychiatry 21: 1070-1076.

Bouton ME. 2004. Context and behavioral processes in extinction. Learn Mem 11: 485-494.

Briggs SB, Blouin AM, Young EJ, Rumbaugh G, Miller CA. 2017. Memory disrupting effects of nonmuscle myosin II inhibition depend on the class of abused drug and brain region. Learn Mem 24: 70-75.

Brunet A, Saumier D, Liu A, Streiner DL, Tremblay J, Pitman RK. 2018. Reduction of PTSD symptoms with pre-reactivation propranolol therapy: a randomized controlled trial. Am J Psychiatry 175: 427-433.

Bustos SG, Giachero M, Maldonado H, Molina VA. 2010. Previous stress attenuates the susceptibility to Midazolam's disruptive effect on fear memory reconsolidation: influence of pre-reactivation D-cycloserine administration. Neuropsychopharmacology 35: 1097-1108.

Cassini LF, Flavell CR, Amaral OB, Lee JLC. 2017. On the transition from reconsolidation to extinction of contextual fear memories. Learn Mem 24: 392-399.

Das RK, Freeman TP, Kamboj SK. 2013. The effects of N-methyl D-aspartate and B-adrenergic receptor antagonists on the reconsolidation of reward memory: a meta-analysis. Neurosci Biobehav Rev 37: 240-255.

Das RK, Hindocha C, Freeman TP, Lazzarino AI, Curran HV, Kamboj SK. 2015. Assessing the translational feasibility of pharmacological drug memory reconsolidation blockade with memantine in quitting smokers. Psychopharmacology (Berl) 232: 3363-3374.

Das RK, Gale G, Hennessy V, Kamboj SK. 2018. A Prediction error-driven retrieval procedure for destabilizing and rewriting maladaptive reward memories in hazardous drinkers. J Vis Exp. doi: 10.3791/56097

Debiec J, Doyère V, Nader K, Ledoux JE. 2006. Directly reactivated, but not indirectly reactivated, memories undergo reconsolidation in the amygdala. Proc Natl Acad Sci 103: 3428-3433.

de Carvalho CR, Takahashi RN. 2017. Cannabidiol disrupts the reconsolidation of contextual drug-associated memories in Wistar rats. Addict Biol 22: 742-751.

de Carvalho CR, Pamplona FA, Cruz JS, Takahashi RN. 2014. Endocannabinoids underlie reconsolidation of hedonic memories in Wistar rats. Psychopharmacology (Berl) 231: 1417-1425.

Dickinson A, Balleine BW. 1994. Motivational control of goal-directed action. Anim Learn Behav 22: 1-18.

Ding Z-B, Wu P, Luo Y-X, Shi H-S, Shen H-W, Wang S-J, Lu L. 2013. Region-specific role of Rac in nucleus accumbens core and basolateral amygdala in consolidation and reconsolidation of cocaine-associated cue memory in rats. Psychopharmacology (Berl) 228: 427-437.

Dunbar AB, Taylor JR. 2016. Inhibition of protein synthesis but not $\beta$-adrenergic receptors blocks reconsolidation of a cocaine-associated cue memory. Learn Mem 23: 391-398.

Dunbar AB, Taylor JR. 2017. Garcinol blocks the reconsolidation of multiple cocaine-paired cues after a single cocaine-reactivation session. Neuropsychopharmacology 42: 1884-1892.

Elsey JWB, Kindt M. 2017. Breaking boundaries: optimizing reconsolidation-based interventions for strong and old memories. Learn Mem 24: 472-479.

Escosteguy-Neto JC, Varela P, Correa-Neto NF, Coelho LS, Onaivi ES, Santos-Junior JG. 2016. Reconsolidation and update of morphine-associated contextual memory in mice. Neurobiol Learn Mem 130: $194-201$.

Everitt BJ, Robbins TW. 2005. Neural systems of reinforcement for drug addiction: from actions to habits to compulsion. Nat Neurosci 8: 1481-1489.

Everitt BJ, Dickinson A, Robbins TW. 2001. The neuropsychological basis of addictive behaviour. Brain Res Brain Res Rev 36: 129-138.

Exton-McGuinness MTJ, Lee JLC. 2015. Reduction in responding for sucrose and cocaine reinforcement by disruption of memory reconsolidation. eNeuro 2 doi: 10.1523/ENEURO.0009-15.2015

Exton-McGuinness MTJ, Patton RC, Sacco LB, Lee JLC. 2014. Reconsolidation of a well-learned instrumental memory. Learn Mem 21: $468-477$.

Exton-McGuinness MTJ, Lee JLC, Reichelt AC. 2015. Updating memories--the role of prediction errors in memory reconsolidation. Behav Brain Res 278: 375-384.

Fan Y-D, Niu H-C, Huma T, Li L, Wang G-M, Xu L-Q, Ren H, Ma Y-Y, Yu H-L. 2013. Blockage of glucocorticoid receptors during memory acquisition, retrieval and reconsolidation prevents the expression of morphine-induced conditioned place preferences in mice. Dongwuxue Yanjiu 34: E26-E34. 
Flavell CR, Lee JLC. 2013. Reconsolidation and extinction of an appetitive Pavlovian memory. Neurobiol Learn Mem 104: 25-31.

García-Pérez D, Ferenczi S, Kovács KJ, Laorden ML, Milanés MV, Núñez C. 2016. Different contribution of glucocorticoids in the basolateral amygdala to the formation and expression of opiate withdrawal-associated memories. Psychoneuroendocrinology 74: 350-362.

Goltseker K, Bolotin L, Barak S. 2017. Counterconditioning during reconsolidation prevents relapse of cocaine memories. Neuropsychopharmacology 42: 716-726.

Hafenbreidel M, Rafa Todd C, Mueller D. 2017. Infralimbic GluN2A-containing NMDA receptors modulate reconsolidation of cocaine self-administration memory. Neuropsychopharmacology 42: 1113-1125.

Hernandez PJ, Kelley AE. 2004. Long-term memory for instrumental responses does not undergo protein synthesis-dependent reconsolidation upon retrieval. Learn Mem 11: 748-754.

Hogarth L. 2012. Goal-directed and transfer-cue-elicited drug-seeking are dissociated by pharmacotherapy: evidence for independent additive controllers. J Exp Psychol Anim Behav Process 38: 266-278.

Hogarth L, Chase HW. 2011. Parallel goal-directed and habitual control of human drug-seeking: implications for dependence vulnerability. J Exp Psychol Anim Behav Process 37: 261-276.

Hon T, Das RK, Kamboj SK. 2016. The effects of cognitive reappraisal following retrieval-procedures designed to destabilize alcohol memories in high-risk drinkers. Psychopharmacology (Berl) 233: 851-861.

Jaffe AB, Hall A. 2005. Rho GTPases: biochemistry and biology. Annu Rev Cell Dev Biol 21: 247-269.

Jasinska AJ, Stein EA, Kaiser J, Naumer MJ, Yalachkov Y. 2014. Factors modulating neural reactivity to drug cues in addiction: a survey of human neuroimaging studies. Neurosci Biobehav Rev 38: 1-16.

Jian M, Luo Y-X, Xue Y-X, Han Y, Shi H-S, Liu J-F, Yan W, Wu P, Meng S-Q, Deng J-H, et al. 2014. eIF2 $\alpha$ dephosphorylation in basolateral amygdala mediates reconsolidation of drug memory. J Neurosci 34: 10010-10021.

Jiménez-Sánchez L, Campa L, Auberson YP, Adell A. 2014. The role of GluN2A and GluN2B subunits on the effects of NMDA receptor antagonists in modeling schizophrenia and treating refractory depression. Neuropsychopharmacology 39: 2673-2680.

Jobes ML, Aharonovich E, Epstein DH, Phillips KA, Reamer D, Anderson M, Preston KL. 2015. Effects of prereactivation propranolol on cocaine craving elicited by imagery script/cue sets in opioid-dependent polydrug users: a randomized study. J Addict Med 9: 491-498.

Kaag AM, Goudriaan AE, De Vries TJ, Pattij T, Wiers RW. 2018. A high working memory load prior to memory retrieval reduces craving in non-treatment seeking problem drinkers. Psychopharmacology (Berl) 235: 695-708.

Kindt M, Soeter M, Vervliet B. 2009. Beyond extinction: erasing human fear responses and preventing the return of fear. Nat Neurosci 12: 256-258.

Lattal KM, Wood MA. 2013. Epigenetics and persistent memory: implications for reconsolidation and silent extinction beyond the zero. Nat Neurosci 16: 124-129.

Lee JLC, Flavell CR. 2014. Inhibition and enhancement of contextual fear memory destabilization. Front Behav Neurosci 8: 144.

Lee JLC, Di Ciano P, Thomas KL, Everitt BJ. 2005. Disrupting reconsolidation of drug memories reduces cocaine-seeking behavior. Neuron 47: 795-801.

Lee JLC, Milton AL, Everitt BJ. 2006. Cue-induced cocaine seeking and relapse are reduced by disruption of drug memory reconsolidation. J Neurosci 26: $5881-5887$

Lee JLC, Bertoglio LJ, Guimarães FS, Stevenson CW. 2017a. Cannabidiol regulation of emotion and emotional memory processing: relevance for treating anxiety-related and substance abuse disorders. $\mathrm{Br} J$ Pharmacol 174: $3242-3256$.

Lee JLC, Nader K, Schiller D. 2017b. An update on memory reconsolidation updating. Trends Cogn Sci 21: 531-545.

Lewis DJ. 1979. Psychobiology of active and inactive memory. Psychol Bull 86: 1054-1083.

Li G, Wang Y, Yan M, Xu Y, Song X, Li Q, Zhang J, Ma H, Wu Y. 2015. Inhibition of actin polymerization in the NAc shell inhibits morphine-induced CPP by disrupting its reconsolidation. Sci Rep 5: 16283.

Li Y, Ge S, Li N, Chen L, Zhang S, Wang J, Wu H, Wang X, Wang X. 2016. NMDA and dopamine D1 receptors within NAc-shell regulate IEG proteins expression in reward circuit during cocaine memory reconsolidation. Neuroscience 315: 45-69.

Liang J, Li J-L, Han Y, Luo Y-X, Xue Y-X, Zhang Y, Zhang Y, Zhang L-B, Chen M-L, Lu L, et al. 2017. Calpain-GRIP signaling in nucleus accumbens core mediates the reconsolidation of drug reward memory. $J$ Neurosci 37: 8938-8951.

Lin J, Liu L, Wen Q, Zheng C, Gao Y, Peng S, Tan Y, Li Y. 2014. Rapamycin prevents drug seeking via disrupting reconsolidation of reward memory in rats. Int J Neuropsychopharmacol 17: 127-136.
Lonergan M, Saumier D, Tremblay J, Kieffer B, Brown TG, Brunet A. 2016. Reactivating addiction-related memories under propranolol to reduce craving: a pilot randomized controlled trial. J Behav Ther Exp Psychiatry 50: $245-249$

Luo Y, Xue Y, Liu J, Shi H, Jian M, Han Y, Zhu W, Bao Y, Wu P, Ding Z, et al. 2015. A novel UCS memory retrieval-extinction procedure to inhibit relapse to drug seeking. Nat Commun 6: 7675.

Lv X-F, Sun L-L, Cui C-L, Han J-S. 2015. NAc shell Arc/Arg3.1 protein mediates reconsolidation of morphine CPP by increased GluR1 cell surface expression: activation of ERK-coupled CREB is required. Int Neuropsychopharmacol 18: pyv030.

Merlo E, Milton AL, Goozee ZY, Theobald DE, Everitt BJ. 2014. Reconsolidation and extinction are dissociable and mutually exclusive processes: behavioral and molecular evidence. J Neurosci 34: 2422-2431.

Merlo E, Ratano P, Ilioi EC, Robbins MALS, Everitt BJ, Milton AL. 2015. Amygdala dopamine receptors are required for the destabilization of a reconsolidating appetitive memory. eNeuro 2 doi: 10.1523/ ENEURO.0024-14.2015.

Merlo E, Milton AL, Everitt BJ. 2018. A novel retrieval-dependent memory process revealed by the arrest of ERK1/2 activation in the basolateral amygdala. J Neurosci 38: 3199-3207.

Mierzejewski P, Korkosz A, Rogowski A, Korkosz I, Kostowski W, Scinska A. 2009. Post-session injections of a protein synthesis inhibitor, cycloheximide do not alter saccharin self-administration. Prog Neuropsychopharmacol Biol Psychiatry 33: 286-289.

Milekic MH, Brown SD, Castellini C, Alberini CM. 2006. Persistent disruption of an established morphine conditioned place preference. $J$ Neurosci 26: $3010-3020$.

Miller CA, Marshall JF. 2005. Molecular substrates for retrieval and reconsolidation of cocaine-associated contextual memory. Neuron 47: 873-884.

Milton AL, Everitt BJ. 2009. P.4.09 NMDA receptors and $\beta$-adrenergic receptors as molecular targets for the prevention of relapse to drug-seeking. Eur Neuropsychopharmacol 19: S86-S87.

Milton AL, Everitt BJ. 2010. The psychological and neurochemical mechanisms of drug memory reconsolidation: implications for the treatment of addiction. Eur J Neurosci 31: 2308-2319.

Milton AL, Everitt BJ. 2012. The persistence of maladaptive memory: addiction, drug memories and anti-relapse treatments. Neurosci Biobehav Rev 36: 1119-1139.

Milton AL, Lee JLC, Butler VJ, Gardner R, Everitt BJ. 2008a. Intra-amygdala and systemic antagonism of NMDA receptors prevents the reconsolidation of drug-associated memory and impairs subsequently both novel and previously acquired drug-seeking behaviors. J Neurosc 28: 8230-8237.

Milton AL, Lee JLC, Everitt BJ. 2008b. Reconsolidation of appetitive memories for both natural and drug reinforcement is dependent on $\{\beta\}$-adrenergic receptors. Learn Mem 15: 88-92.

Milton AL, Schramm MJW, Wawrzynski JR, Gore F, Oikonomou-Mpegeti F, Wang NQ, Samuel D, Economidou D, Everitt BJ. 2012. Antagonism at NMDA receptors, but not $\beta$-adrenergic receptors, disrupts the reconsolidation of Pavlovian conditioned approach and instrumental transfer for ethanol-associated conditioned stimuli. Psychopharmacology (Berl) 219: 751-761.

Milton AL, Merlo E, Ratano P, Gregory BL, Dumbreck JK, Everitt BJ. 2013. Double dissociation of the requirement for GluN2B- and GluN2A-containing NMDA receptors in the destabilization and restabilization of a reconsolidating memory. J Neurosci 33: 1109-1115.

Monsey MS, Sanchez H, Taylor JR. 2017. The naturally occurring compound garcinia indica selectively impairs the reconsolidation of a cocaine-associated memory. Neuropsychopharmacology 42: 587-597.

Morgan CJA, Muetzelfeldt L, Curran HV. 2010. Consequences of chronic ketamine self-administration upon neurocognitive function and psychological wellbeing: a 1-year longitudinal study. Addiction 105: 121-133.

Murray JE, Belin D, Everitt BJ. 2012. Double dissociation of the dorsomedial and dorsolateral striatal control over the acquisition and performance of cocaine seeking. Neuropsychopharmacology 37: 2456-2466.

Oliveira AMM. 2016. DNA methylation: a permissive mark in memory formation and maintenance. Learn Mem 23: 587-593.

Ostlund SB, Balleine BW. 2008. On habits and addiction: an associative analysis of compulsive drug seeking. Drug Discov Today Dis Models 5: 235-245.

Otis JM, Mueller D. 2017. Reversal of cocaine-associated synaptic plasticity in medial prefrontal cortex parallels elimination of memory retrieval. Neuropsychopharmacology 42: 2000-2010.

Otis JM, Dashew KB, Mueller D. 2013. Neurobiological dissociation of retrieval and reconsolidation of cocaine-associated memory. J Neurosci 33: $1271-1281 \mathrm{a}$

Otis JM, Fitzgerald MK, Mueller D. 2014. Inhibition of hippocampal $\beta$-adrenergic receptors impairs retrieval but not reconsolidation of 
cocaine-associated memory and prevents subsequent reinstatement. Neuropsychopharmacology 39: 303-310.

Pachas GN, Gilman J, Orr SP, Hoeppner B, Carlini SV, Grasser EB, Loebl T, Nino J, Pitman RK, Evins AE. 2015. Single dose propranolol does not affect physiologic or emotional reactivity to smoking cues. Psychopharmacology (Berl) 232: 1619-1628.

Pastuzyn ED, Day CE, Kearns RB, Kyrke-Smith M, Taibi AV, McCormick J, Yoder N, Belnap DM, Erlendsson S, Morado DR, et al. 2018. The neuronal gene arc encodes a repurposed retrotransposon gag protein that mediates intercellular RNA transfer. Cell 172: 275-288.e18.

Pedreira MEME, Maldonado H. 2003. Protein synthesis subserves reconsolidation or extinction depending on reminder duration. Neuron 38: $863-869$.

Rammes G, Danysz W, Parsons CG. 2008. Pharmacodynamics of memantine: an update. Curr Neuropharmacol 6: 55-78.

Reichelt AC, Lee JLC. 2012. Appetitive Pavlovian goal-tracking memories reconsolidate only under specific conditions. Learn Mem 20: 51-60.

Reichelt AC, Exton-McGuinness MT, Lee JLC. 2013. Ventral tegmental dopamine dysregulation prevents appetitive memory destabilization. $J$ Neurosci 33: 14205-14210.

Ren Z-Y, Liu M-M, Xue Y-X, Ding Z-B, Xue L-F, Zhai S-D, Lu L. 2013. A critical role for protein degradation in the nucleus accumbens core in cocaine reward memory. Neuropsychopharmacology 38: 778-790.

Rich MT, Abbott TB, Chung L, Gulcicek EE, Stone KL, Colangelo CM, Lam TT, Nairn AC, Taylor JR, Torregrossa MM. 2016. Phosphoproteomic analysis reveals a novel mechanism of CaMKII $\alpha$ regulation inversely induced by cocaine memory extinction versus reconsolidation. $J$ Neurosci 36: 7613-7627.

Robinson TE, Berridge KC. 2008. The incentive sensitization theory of addiction: some current issues. Philos Trans R Soc B Biol Sci 363: 3137-3146.

Saladin ME, Gray KM, McRae-Clark AL, Larowe SD, Yeatts SD, Baker NL, Hartwell KJ, Brady KT. 2013. A double blind, placebo-controlled study of the effects of post-retrieval propranolol on reconsolidation of memory for craving and cue reactivity in cocaine dependent humans. Psychopharmacology (Berl) 226: 721-737.

Sanchez H, Quinn JJ, Torregrossa MM, Taylor JR. 2010. Reconsolidation of a cocaine-associated stimulus requires amygdalar protein kinase A. J Neurosci 30: 4401-4407.

Schramm MJW, Everitt BJ, Milton AL. 2016. Bidirectional modulation of alcohol-associated memory reconsolidation through manipulation of adrenergic signaling. Neuropsychopharmacology 41: 1103-1111.

Shi X, Miller JS, Harper LJ, Poole RL, Gould TJ, Unterwald EM. 2014 Reactivation of cocaine reward memory engages the Akt/GSK3/mTOR signaling pathway and can be disrupted by GSK3 inhibition. Psychopharmacology (Berl) 231: 3109-3118.

Shi H-S, Luo Y-X, Yin X, Wu H-H, Xue G, Geng X-H, Hou Y-N. 2015. Reconsolidation of a cocaine associated memory requires DNA methyltransferase activity in the basolateral amygdala. Sci Rep 5: 13327.

Singer BF, Fadanelli M, Kawa AB, Robinson TE. 2018. Are cocaine-seeking "habits" necessary for the development of addiction-like behavior in rats? J Neurosci 38: 60-73.

Sjoerds Z, van den Brink W, Beekman ATF, Penninx BWJH, Veltman DJ. 2014. Cue reactivity is associated with duration and severity of alcohol dependence: an FMRI study. PLoS One 9: e84560.

Slaker M, Churchill L, Todd RP, Blacktop JM, Zuloaga DG, Raber J, Darling RA, Brown TE, Sorg BA. 2015. Removal of perineuronal nets in the medial prefrontal cortex impairs the acquisition and reconsolidation of a cocaine-induced conditioned place preference memory. J Neurosci 35: 4190-4202.

Sorg BA, Todd RP, Slaker M, Churchill L. 2015. Anisomycin in the medial prefrontal cortex reduces reconsolidation of cocaine-associated memories in the rat self-administration model. Neuropharmacology 92: 25-33.

Stern CAJ, de Carvalho CR, Bertoglio LJ, Takahashi RN. 2018. Effects of cannabinoid drugs on aversive or rewarding drug-associated memory extinction and reconsolidation. Neuroscience 370: $62-80$.

Stringfield SJ, Higginbotham JA, Wang R, Berger AL, McLaughlin RJ, Fuchs RA. 2017. Role of glucocorticoid receptor-mediated mechanisms in cocaine memory enhancement. Neuropharmacology 123: 349-358.

Subramanian S, Bates SE, Wright JJ, Espinoza-Delgado I, Piekarz RL. 2010. Clinical toxicities of histone deacetylase inhibitors. Pharmaceuticals 3: 2751-2767.

Tedesco V, Mutti A, Auber A, Chiamulera C. 2014. Nicotine-seeking reinstatement is reduced by inhibition of instrumental memory reconsolidation. Behav Pharmacol 25: 725-731.

Théberge FRM, Milton AL, Belin D, Lee JLC, Everitt BJ. 2010. The basolateral amygdala and nucleus accumbens core mediate dissociable aspects of drug memory reconsolidation. Learn Mem 17: 444-453.
Tiffany ST, Conklin CA, Shiffman S, Clayton RR. 2004. What can dependence theories tell us about assessing the emergence of tobacco dependence? Addiction 99: 78-86.

Valjent E, Corbillé A-G, Bertran-Gonzalez J, Hervé D, Girault J-A. 2006. Inhibition of ERK pathway or protein synthesis during reexposure to drugs of abuse erases previously learned place preference. Proc Natl Acad Sci 103: 2932-2937.

Vanderschuren LJMJ, Di Ciano P, Everitt BJ. 2005. Involvement of the dorsal striatum in cue-controlled cocaine seeking. J Neurosci 25: 8665-8670.

Vengeliene V, Olevska A, Spanagel R. 2015. Long-lasting effect of NMDA receptor antagonist memantine on ethanol-cue association and relapse. J Neurochem 135: 1080-1085.

Volkow ND, Wang G-J, Telang F, Fowler JS, Logan J, Childress A-R, Jayne M, Ma Y, Wong C. 2006. Cocaine cues and dopamine in dorsal striatum: mechanism of craving in cocaine addiction. J Neurosci 26: 6583-6588.

Wan X, Torregrossa MM, Sanchez H, Nairn AC, Taylor JR. 2014. Activation of exchange protein activated by cAMP in the rat basolateral amygdala impairs reconsolidation of a memory associated with self-administered cocaine. PLoS One 9: e107359.

Wang D, Fawcett J. 2012. The perineuronal net and the control of CNS plasticity. Cell Tissue Res 349: 147-160.

Wang S-H, Ostlund SB, Nader K, Balleine BW. 2005. Consolidation and reconsolidation of incentive learning in the amygdala. J Neurosci $\mathbf{2 5}$ $830-835$.

Wang M, Chazot PL, Ali S, Duckett SF, Obrenovitch TP. 2012. Effects of NMDA receptor antagonists with different subtype selectivities on retinal spreading depression. Br J Pharmacol 165: 235-244.

Wei S, Li X. 2014. Differential effects of propranolol on conditioned hyperactivity and locomotor sensitization induced by morphine in rats. Sci Rep 4: 3786.

Wells AM, Arguello AA, Xie X, Blanton MA, Lasseter HC, Reittinger AM, Fuchs RA. 2013. Extracellular signal-regulated kinase in the basolateral amygdala, but not the nucleus accumbens core, is critical for context-response-cocaine memory reconsolidation in rats. Neuropsychopharmacology 38: 753-762.

Wells AM, Xie X, Higginbotham JA, Arguello AA, Healey KL, Blanton M, Fuchs RA. 2016. Contribution of an SFK-mediated signaling pathway in the dorsal hippocampus to cocaine-memory reconsolidation in rats. Neuropsychopharmacology 41: 675-685.

Wu Y, Li Y, Yang X, Sui N. 2014. Differential effect of $\beta$-adrenergic receptor antagonism in basolateral amygdala on reconsolidation of aversive and appetitive memories associated with morphine in rats. Addict Biol 19: $5-15$.

Xue YX, Luo YX, Wu P, Shi HS, Xue LF, Chen C, Zhu WL, Ding ZB, Bao YP, Shi J, et al. 2012. A memory retrieval-extinction procedure to prevent drug craving and relapse. Science 336: 241-245.

Xue YX, Chen YY, Zhang LB, Zhang LQ, Huang GD, Sun SC, Deng JH, Luo YX, Bao YP, Wu P, et al. 2017. Selective inhibition of amygdala neuronal ensembles encoding nicotine-associated memories inhibits nicotine preference and relapse. Biol Psychiatry 82: 781-793.

Yan Y, Newman AH, Xu M. 2014. Dopamine D1 and D3 receptors mediate reconsolidation of cocaine memories in mouse models of drug self-administration. Neuroscience 278: 154-164.

Yu YJ, Chang CH, Gean PW. 2013. AMPA receptor endocytosis in the amygdala is involved in the disrupted reconsolidation of Methamphetamine-associated contextual memory. Neurobiol Learn Mem 103: 72-81.

Yu YJ, Huang CH, Chang CH, Gean PW. 2016. Involvement of protein phosphatases in the destabilization of methamphetamine-associated contextual memory. Learn Mem 23: 486-493.

Zapata A, Minney VL, Shippenberg TS. 2010. Shift from goal-directed to habitual cocaine seeking after prolonged experience in rats. J Neurosci 30: $15457-15463$.

Zhang Y, Xue Y, Meng S, Luo Y, Liang J, Li J, Ai S, Sun C, Shen H, Zhu W, et al. 2016. Inhibition of lactate transport erases drug memory and prevents drug relapse. Biol Psychiatry 79: 928-939.

Zhu H, Zhou Y, Liu Z, Chen X, Li Y, Liu X, Ma L. 2017. $\beta 1$-adrenoceptor in the central amygdala is required for unconditioned stimulus-induced drug memory reconsolidation. Int J Neuropsychopharmacol 21: 267-280.

Zinck R, Cahill MA, Kracht M, Sachsenmaier C, Hipskind RA, Nordheim A. 1995. Protein synthesis inhibitors reveal differential regulation of mitogen-activated protein kinase and stress-activated protein kinase pathways that converge on Elk-1. Mol Cell Biol 15: 4930-4938.

Received March 26, 2018; accepted in revised form May 21, 2018. 

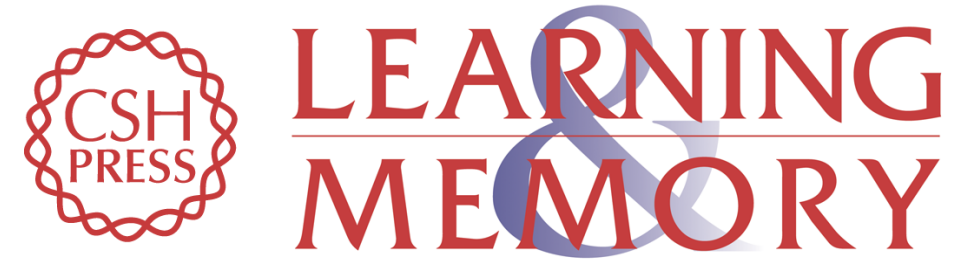

\section{Reconsolidation blockade for the treatment of addiction: challenges, new targets, and opportunities}

Marc T.J. Exton-McGuinness and Amy L. Milton

Learn. Mem. 2018, 25:

Access the most recent version at doi:10.1101/Im.046771.117

\begin{aligned} & \hline References $\begin{array}{l}\text { This article cites } 132 \text { articles, } 37 \text { of which can be accessed free at: } \\ \text { http://learnmem.cshlp.org/content/25/9/492.full.html\#ref-list-1 }\end{array} \\ & \begin{array}{r}\text { Creative } \\ \text { Commons } \\ \text { License }\end{array} \begin{array}{l}\text { This article is distributed exclusively by Cold Spring Harbor Laboratory Press for the } \\ \text { first } 12 \text { months after the full-issue publication date (see } \\ \text { http://learnmem.cshlp.org/site/misc/terms.xhtml). After } 12 \text { months, it is available under } \\ \text { a Creative Commons License (Attribution-NonCommercial } 4.0 \text { International), as } \\ \text { described at http://creativecommons.org/licenses/by-nc/4.0/. }\end{array} \\ & \begin{array}{c}\text { Receive free email alerts when new articles cite this article - sign up in the box at the } \\ \text { top right corner of the article or click here. }\end{array} \\ & \begin{array}{l}\text { Service } \\ \text { terting }\end{array}\end{aligned}$

